\title{
Women's Entrepreneurial Ecosystem in Nepal: A Study Based on Kathmandu Valley
}

\author{
Upasna Acharya, Faculty \\ UpasnaAcharya@westcliff.edu
}

\author{
Chittaranjan Pandey, Faculty \\ chittaranjanpandey@westcliff.edu
}

\begin{abstract}
Entrepreneurship, traditionally seen as a male preserve, has witnessed increasing participation from females in recent years. Across the world, the number of enterprises being run by women is growing exponentially. Nepal is not an exception to this emerging trend. However, there are embedded structural and socio-cultural constraints which pose a challenge to the growth of women entrepreneurs and the stability of the entrepreneurial ecosystem in Nepal. Through qualitative research, this article attempts to study the phenomenon of the entrepreneurship of women and explore the status-quo and the policy framework for female entrepreneurs in Nepal. This article explores the current entrepreneurial environment for Nepalese women, as well as the issues and challenges associated with it. This study was conducted within the Kathmandu valley and samples of the study were drawn from various stakeholders comprising of financial institutions, government agencies, I/NGOs, venture capitalists and women entrepreneurs. The data required for the study was obtained via in-depth personal interviews, key informants' interviews and literature reviews from a variety of well-researched journals and articles. The sixfactor model, inclusive of social, economic, competitive, facilitating, locational and political aspects identified by Bulsara, Chandwani and Gandhi (2014), has been assessed to understand the inherent challenges. Additionally, a political, economic, social, technological, environmental and legal (PESTEL) framework has been used to analyse insights from current women in the Nepalese entrepreneurial ecosystem. This study revealed that the process of lengthy documentation, bureaucratic hassles, political uncertainty, unconducive business environments, corruption, strikes, and unionization are the concurrent factors affecting the entrepreneurial environment in Nepal. On the policy side, though an amendment has been made in the Nepal Enterprise Act to support the entrepreneurship of women, the effectiveness of the policy support is still questioned.
\end{abstract}




\section{INTRODUCTION}

Women entrepreneurship refers to the innovation, initiation and operation of any business by that of a woman (Kumar, Navalgund, Mohan, \& Vijaya, 2013). Findings from Cohoon, Wadhwa and Mitchell (2011), list empowerment, self-reliance, financial stability and independence as key factors motivating females to step into the entrepreneurial journey.

Women entrepreneurship in Nepal is still in the evolving process. According to Dwibedi (2015), the surrogate entrepreneurship culture evident in Nepal makes the task of capturing the actual number of women entrepreneurs very difficult. Many women, though registered as entrepreneurs, do not operate the ventures. The enterprises they own are either run by their husbands or another male family member. Nepal still follows the feudalism of cultural norms and beliefs which prevent women from being entrepreneurs ("Green tick Nepal," 2018). The embedded structural and socio-cultural constraints have highly challenged the growth and stability of the entrepreneurial ecosystem. In many parts of the country, women are viewed as a vulnerable population and are subjected to unfair treatment which binds them to break the blockages and act on their own will ("Green tick Nepal," 2018). As per the United Nation's (2018) records, women constitute 50.4 percent of Nepal's population. Despite representing half of the country's population and being a better half of the society, female participation is relatively low in the economic sector, which is why women entrepreneurship in Nepal is yet to gain momentum.

\section{Objectives of the Study}

The general objective of this study is to understand the current entrepreneurial environment for women and the issues and challenges associated with this sector in the context of Nepal.

The specific objectives of the study are:

i. To explore the overall entrepreneurial environment for women in Nepal.

ii. To assess the contribution of the supporting agencies like I/NGOs, financial institutions-commercial and development banks, government agencies and venture capitalists in promoting women entrepreneurship in Nepal.

\section{Methodology}

Kathmandu valley is the social, political and financial hub of the country. Kathmandu and Lalitpur metropolitan, cities which are two contiguous and closely looped administrative cities (Thapa, Murayama, \& Ale, 2008), were selected for the study. Qualitative research design and the convenience sampling method was used for finding the appropriate respondents. The sampling technique as of Llorente, Lopez, \& Montes (2011) was followed. Seven sample points were determined to capture the heterogeneity and diverse respondents in the study. A total of ninety-two samples were selected randomly from sample points and were further broken down as per the requirement in each district. The sample covered respondents from NGOs/INGOs, financial institutionscommercial and development banks, government offices, venture capitals, startups and private enterprises. The research design for this project can be seen below in Figure 1. 


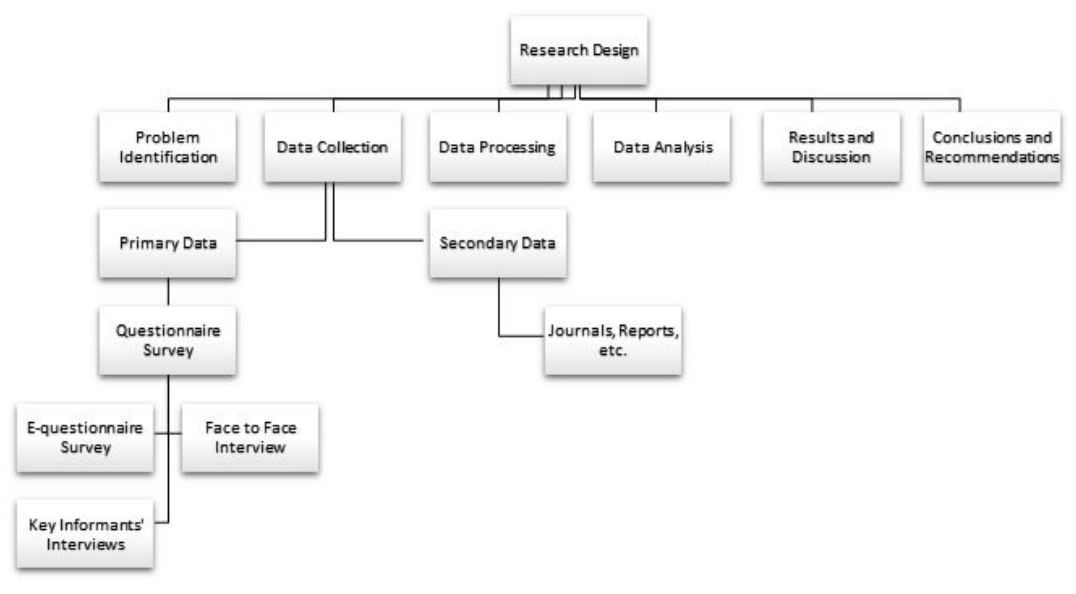

Figure 1. Research design followed for the study.

As can be seen, the primary data was collected via personal interviews, key informant interviews and mailed questionnaires. The key informants for the study were respondents from the credit departments in commercial and development banks, representatives of I/NGOs, government officers, owners of private organizationsventure capitals, law firm and colleges. Faceto-face interviews with selected entrepreneurs were also conducted to gain insights related to entrepreneurship programs and their effectiveness.

\section{DATA ANALYSIS}

Most of the data obtained was qualitative and descriptive in nature. Triangulation of ideas was carried out and the responses obtained were compared and contrasted with previous academic literature related to women entrepreneurship. The study used the phenomenological approach for the analysis of the data. The fundamental goal of the phenomenological approach is to arrive at a description of the nature of a particular phenomenon (Creswell, 2013). Under the phenomenological orientation, persons with deeper understandings of the entrepreneurial ecosystem and experiences were identified; their experiences of entrepreneurial aspects were recorded, transcribed and interpreted. Collected data was processed and further analyzed with the help of Microsoft Excel 2010.

\section{THEORETICAL FRAMEWORK}

The conceptual framework, developed by Bulsara, Chandwani, and Gandhi (2014) identifies six factors that affect and challenge women entrepreneurship: social factors, economic factors, competitive factors, facilitating factors, locational mobility of entrepreneurs, and other factors. Social factors include childhood, background, education, religion, community setup and cultural issues, support from spouse/family/relatives/community, social mobility and work-life balance. Usually in Nepalese society, women have a lower societal position than men and are expected to work at home. They do not have complete support from their families to enter into the entrepreneurial world (Acharya, 2001). Male members of families do not want to invest their capital in a business run by a woman due to a lack of confidence in women's ability to run a venture successfully. Even if a woman 
receives the familial support to work outside of the home, it is generally within the confines of a corporate job.

Economic factors refer to financial assistance, size of the market, and a lack of access to credit. A lack of financial support is the most common reason as to why many women are unable to start an enterprise (Sashikumar, 2017). In Nepal, women have lesser access to financial resources when compared to their male counterparts. They are not entitled to property rights which deprive them of tangible assets which can be used as a collateral for obtaining funds from external sources.

Competitive factors involve potential entrants, rivalry of firms and substitute products, and cut-throat competition. In Nepalese communities, people start their businesses as a rivalry. "If s/he can do it, I can do it too" is a common thought driving people to start businesses. According to Acharya (2001), a majority of small and medium enterprises owned by females lack prior market research and business knowledge due to which women proprietors face severe problems operating business. Lack of access to marketing networks, marketing information and appropriate business education deprive women entrepreneurs of voice and say in mainstreaming their concerns.

The facilitating factors include training, mentoring and exposure to a business environment. Networks and business associations play an important role in support, training, information management, and access to mentors, role models, and resources (Sattar, 2010). Women entrepreneurs in Nepal are disadvantaged because formal and informal networks and business development services are largely dominated by men. Women, thus, lack exposure, inhibiting their prospects of growth and expansion. Low participation in trainings, limited access to modern management methods, technology and consulting services are pertinent challenges faced by women entrepreneurs in Nepal.

When it comes to locational mobility, unlike men, women's mobility in Nepal is highly limited due to the socio-structural constraints. Women are obliged to access resources through family and spouses. A single woman running a business is still looked upon with suspicion. The cumbersome exercise involved in the registration and operation of business compels women to give up the idea of starting their own venture and instead turn to a corporate job or domestic work. Other factors for giving up include a lack of selfconfidence and risk-taking capacity, as well as male domination in the productive sector. Mainstream research, policies and programs tend to be "men streamed" and too often do not take into account the specific needs of women entrepreneurs and would-be women entrepreneurs (Acharya, 2001), thereby, limiting their substantial participation entrepreneurship. These challenges can be summarized as seen below in Figure 2. 


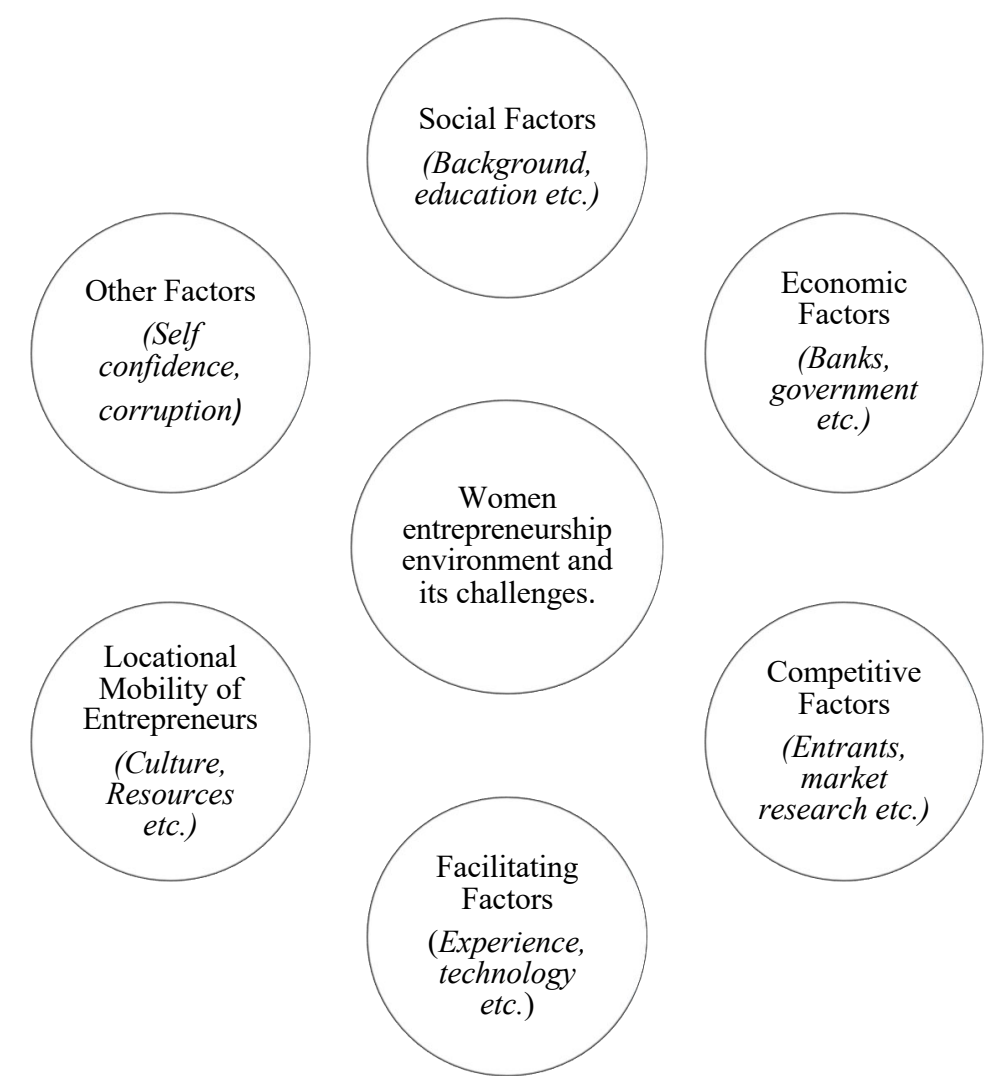

Figure 2. Theoretical framework for women entrepreneurs and challenges faced. (Bulsara, Chandwani, \& Gandhi, 2014).

ENTREPRENEURSHIP IN NEPAL: HISTORY AND TRENDS

The history of entrepreneurship in Nepal dates back prior to the unification of the country. The Mallas, who ruled then, married Bhrikuti to the Tibetan emperor, Srong Btsan Sgam Po. This partnership improved the relationship between Nepal and Tibet, especially in regard to the trade of Buddhist philosophy and art. Nepal was known for its unique art and crafts. People made wooden, metal, and stone crafts that reflected the culture of Nepal and incorporated elements of Buddhism. This might have been the first entrepreneurial step in the history of Nepal (Shakya, 2008). Since then, the trend of entrepreneurship in Nepal has been on the incline. There are a variety of startups, social and commercial enterprises emerging in the market. The idea of entrepreneurship has also been integrated into the educational system, as entrepreneurial courses. Some of the business colleges in Nepal run incubation centers, which incubate and transform the ideas of individuals into concrete business projects. These centers facilitate the growth of social and commercial entrepreneurship through academic teaching, training, mentoring, networking, and most importantly, providing access to seed capital for establishing startups. In addition to this, the emergence of venture capitals has also supported the growth and development of the entrepreneurial sector in the country.

\section{Eco-political Situation in Nepal}

The eco-political situation in Nepal is not considered favorable for establishment of a business. This is due to the fact that the 
process of business registration and operational procedures is a hassle. Nepal is ranked $110^{\text {th }}$ among 190 economies in the ease of doing business, according to the latest World Bank (2018) annual ratings. The continued political disputes, complex tax regime, weak institutional capacity to enforce contracts standing, electricity standing, construction permit etc. attributes to this lower position ("Nepal slips 5 places," 2018).

If we compare the index of doing business presented by the World Bank, the report will help us know how friendly the economy is for the females.

\section{Time taken to start a business, female (Days)}

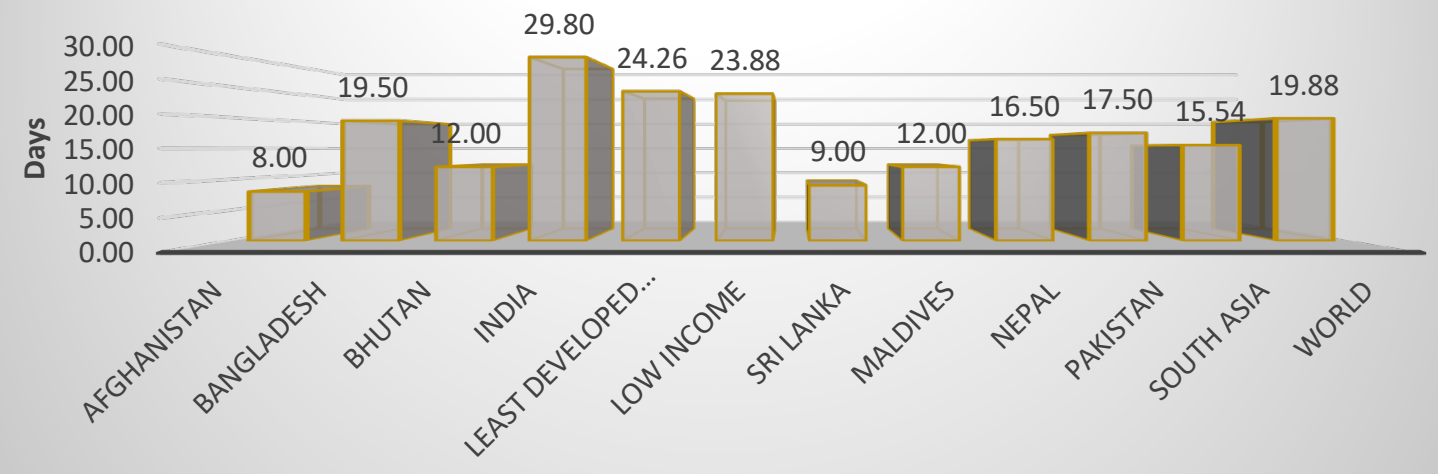

Countries

Figure 3. Time taken to start a business by female. ("The world bank in Nepal," 2016).

The graph shows the time taken (in days) to start a business by females in the South Asian region. It also compares this to the world average. According to the graph, Nepal takes almost 17 days to start a business, which is less than the number of days shown as the average of low-income countries and the world average, but it is a larger number of days than the average of South Asia (15.54 days). Nepal thus, lies in the middle for the duration required to start a business for all South Asian countries.
Similarly, if we compare Nepal with the top five countries of the world, in terms of doing business, we can see that these countries, on average, take 2.2 days for entrepreneurs to start a business, whereas Nepal requires more than 15 days to accomplish the same feat. This implies that Nepal still needs to learn a lot from these countries regarding policy and business environment. The number of days required to start a business can be seen by country in Figure 4. 


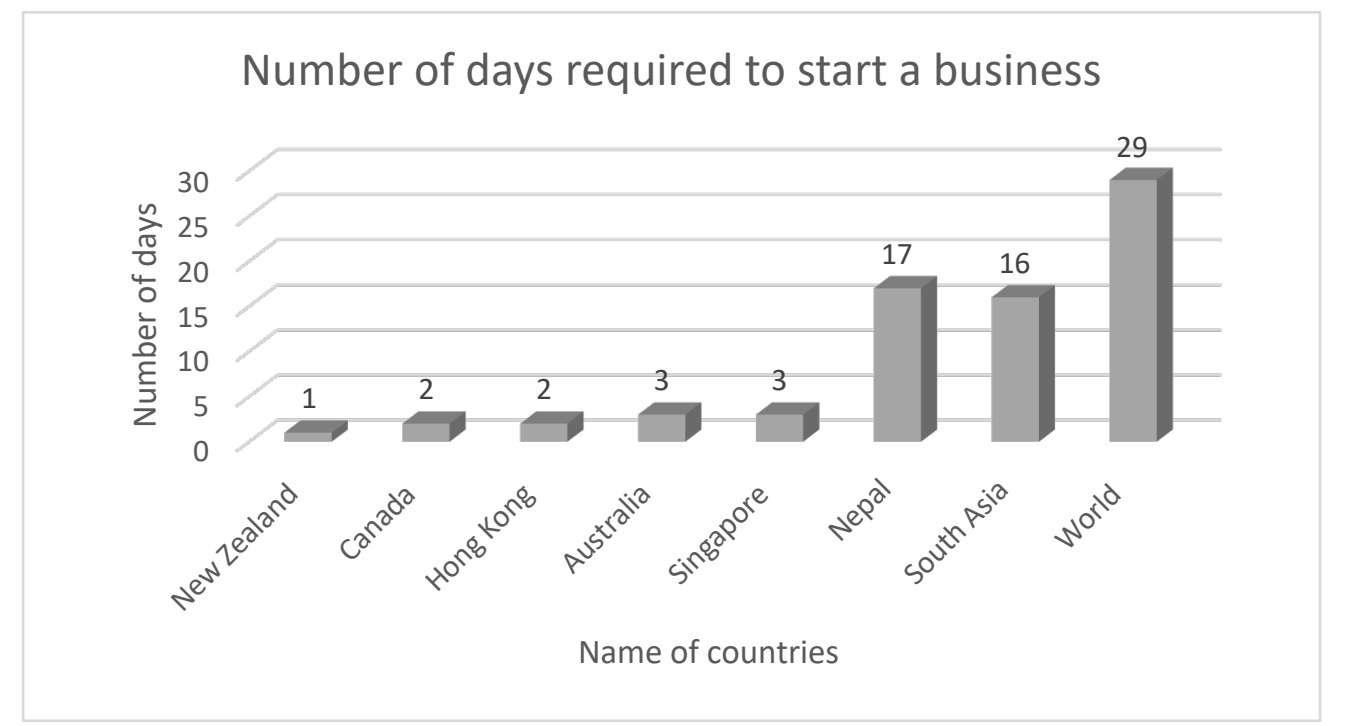

Figure 4. Number of days required to start business. ("The world bank in Nepal," 2016).

Another constraint of doing business in Nepal is that private businesses are required to follow 130 processes from 41 different ministries ("The World Bank in Nepal," 2016). Additionally, corruption is extremely high in Nepal. It was ranked as $130^{\text {th }}$ out of 175 countries in 2015 ("Transparency international," 2017). Bribery has become so infused within the bureaucratic system in Nepal that the pace for business registration has been impacted when there is an absence of bribes. For the reasons aforementioned, it can be concluded that Nepal presents a difficult entrepreneurial environment.

To make a further study the entrepreneurial environment in Nepal, a PESTEL analysis was carried out which included analysis of political, economic, socio-cultural, technical and legal environments. The elements of the PESTEL analysis can be seen below in Figure 5.

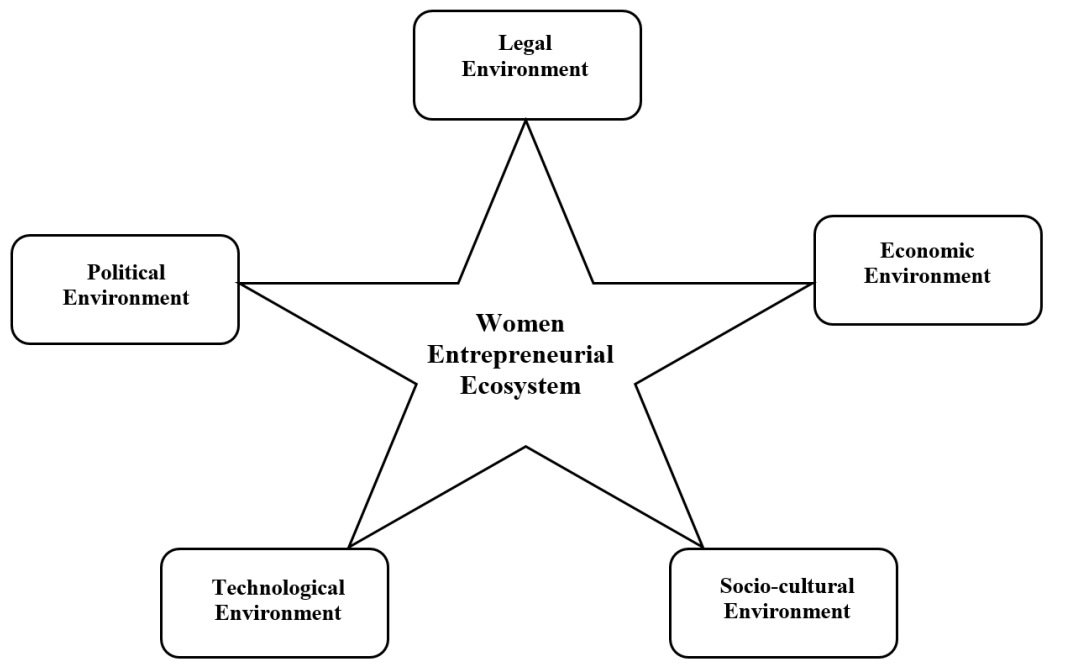

Figure 5. PESTEL framework to study the women entrepreneurial environment in Nepal. 
WOMEN ENTREPRENEURIAL ECOSYSTEM ANALYSIS Legal Environment

Different countries have different legal terms and procedures regarding entrepreneurship and the starting of a business. According to USAID's chief economist, Steve Radelet, the significant requirements for women entrepreneurs in terms of legal and regulatory frameworks differ between countries from property rights to access to finance options. Similarly, women entrepreneurs face a myriad of legal and regulatory challenges that prevent them from starting new businesses.

Nepal's constitutional and legislative framework has become more gender friendly with the intention of raising the social and economic status of women in the country. According to the Central Bureau of Statistics (CBS) (2011), female headed households have increased from 14.57 percent in 2001 to 25.73 percent in 2011.

A way Nepal has attempted to assist women is seen through the registration of land. If land is registered in the name of a woman, she would receive 20 percent off in the tax payment. After this law passed, registration of land and property in the names of women rose to 19.71 percent from 9.11 percent in the previous census (CBS, 2011). This proves that, the current law is influencing the power distribution in small but powerful ways.

According to a Nepalese law enacted in 2011, if a business is registered as solely owned by a woman, the business will receive 35 percent off of the registration fee. In addition, women can receive 20 percent discounts for patents and other intellectual property rights ("Government of Nepal," 2011). Currently, it is very difficult to estimate the actual number of women entrepreneurs in Nepal due to the absence of up-to-date data. According to the findings obtained from the financial institutions, I/NGO's, government agencies and venture capitalists surveyed, women entrepreneurs are being supported at various levels. Financial institutions, such as commercial banks, development banks, and micro credits are providing loans, credits and other possible benefits. I/NGOs provide seed money, functional and financial literacy trainings, mentoring, counselling and leadership development skill trainings. The government provides tax rebates, concessions in the process of registration, entrepreneurship funds, reservations of seats and scholarships in technical education, etc., while venture capitalists support via mentoring, counselling and providing networking opportunities.

However, it is unclear who is actually controlling or running the businesses that have been registered in the name of women. A trend has developed for registering businesses under a woman, solely for the tax benefits. This is continuing to increase as the Nepal Enterprise Act 2016 has been passed, promoting woman entrepreneurship by offering rebates in registration, income tax, and remuneration income. Despite all the efforts of supporting agencies to empower women as entrepreneurs, the status of women has not changed as expected. According to the gender development index (GDI), socioeconomic conditions for Nepalese women is very not good. Nepal ranks $134^{\text {th }}$ among 156 countries in terms of the GDI ("The World Bank in Nepal," 2016).

\section{Economic Environment}

Nepal is an agrarian economy with a population of 28.51 million and a gross domestic product of 21.19 billion dollars ("The World Bank in Nepal," 2016). Development assistance, agricultural enterprises, tourism, exports of carpets and garments and the 
remittances of millions of Nepalese working abroad, play important role in the Nepalese economy (Maskey, 2014). According to Simoes (2016), the top exports of Nepal are flavored water (USD92.2M), knotted carpets (USD75.7M), non-retail synthetic staple fibers yarn (USD58.4M), nutmeg (USD34.3M) and other plastic products (USD33.2M). The majority of these exports are in China, India, United Arab Emirates, United States and some European countries. In recent years, the export base to China has improved equating to 55.3 percent of the total exports, while merchandise exports to India rose by 22.6 percent (Tripathi, 2016). Additionally, outgoing migrant workers have decreased by 8.9 percent according to the department of foreign employment and thus, remittance in Nepal has also been continuously decreasing.

The liquidity management of the economy has also been challenging as financial institutions have not been able to facilitate the entrepreneurial environment. Since the exports have been slightly positive towards China, it is high time women entrepreneurs tap the opportunity and begin to produce items such as agricultural products, handicrafts, garments, which have not been made commercial or been dominated by male business society.

\section{Political Environment}

The political environment of a country plays a vital role in the growth and expansion of businesses. In a country like Nepal, where a multi-party system exists, untimely formation and dissolution of the government has ravaged the policy-making and execution of drafted policies. The Worldwide Governance Indicators ranked Nepal in the bottom 20th percentile for political stability out of 200 countries ("The World Bank in Nepal," 2016). The prevailing uncertainty in the political system has not just dampened entrepreneurial activity but has affected the macroeconomic environment. The frequent changes in government structure, policies, reforms, laws and regulations have constrained both domestic and foreign investments, which in turn stops newcomers from entering into the entrepreneurial ecosystem.

The bureaucratic system has had a major impact on entrepreneur's lives. According to Sorensen (2006), the characteristics of bureaucratic organizations may create frustration, political disruptions and lost opportunities for individuals who are attempting to pursue new ideas. In the context of Nepal, bureaucratic hassles are one of the major concerns. The lengthy conventional documentation process and the centralized and exclusionary system where people from outside the valley have to come to Kathmandu, the capital city for business registration presents territorial hurdles within the country. The evolving bureaucratic system is dominated by bribery. Bribery has become fundamental to progressing through each step of the registration process and results in discouraging entrepreneurs and worsening situations.

$$
\text { Political challenges include }
$$

unionization in the production process. Each political party in Nepal has its own labor union. Such unions are considered powerful by their respective governments. They pressure the government to fulfil their self-based interests by holding demonstrations, calling for strikes, locking up the industries, protesting, etc. The affiliation of labor organizations with political parties and leaders compel management to compromise with labor union demands even against the interests of an enterprise or the nation as a whole.

\section{Socio-cultural Environment}

Nepal is rich in terms of socio-cultural diversity. Despite the diversity, the patriarchal system is still dominant ("Green tick Nepal," 
2018). Even though gender equality, leading to equity and equal opportunity are fundamental rights in Nepal, different standards of behavior for men and women exist. The lower participation of women in entrepreneurship is the outcome of societal standards and beliefs which view women as homemakers rather than innovators or change makers.

In Nepal, entrepreneurship has always been a male preserve. Women's participation in meaningful business experiences are limited by various socio-cultural factors. Women face specific obstacles such as family responsibilities, restrictions on spatial mobility and limited social capital that must be overcome in order to give them access to entrepreneurial opportunities. In addition, the society in Nepal, of which the woman is an integral part, does not believe in a woman's capacity to operate a business (Acharya, 2001). Many times, a family's reluctance to invest their capital has impaired the growth of women-led ventures. When it comes to requesting loans, even the financial institutions demand the presence of a male member or the need for tangible collateral which women have little access to. This clearly displays the lack of trust the Nepalese society puts in the capability of women to run a business independently.

If we look at the positive side, the increasing number of enterprises initiated, run, and managed by women marks a transformation of the Nepalese society. "The formation of self-help groups (SHGs), support from I/NGOs, higher levels of education, and economic liberalization can be considered reasons for this change" states, Rita Bhandari, former president of Federation of Women Entrepreneurs' Association of Nepal (FWEAN). However, despite all of this support, female entrepreneurs are still far from being on par with men.

\section{Technological Environment}

Business and technology are complementary to each other. Technology advancement increases production, effective use of resources, and brings an opportunity to upgrade business firms. Technology is not only a driving force for economic growth and entrepreneurial ventures, but it also acts as a powerful factor able to shape entrepreneurs' behaviors, values, and mindsets.

The process of entrepreneurship involves the use of technology at every step whether that be idea generation, idea selection, resource assemblage, production, marketing, customer satisfaction or any other aspect related to the development of the enterprise. In this perspective, technology is not a neutral tool but something that supports and constrains human action, thinking and even deepest values. Each technological innovation brings with it a wave of new start-ups and new entrepreneurs. Women entrepreneurs in Nepal are well-represented in small and medium enterprises that are based primarily on the subsistence level of technology and production. The growing number of women who own businesses in Nepal, is concentrated mostly in retail trade, home based operations, and personal service industries (Maskey, 2014).

Since mass scale of production is important for economic empowerment and technology is vital for the same, it is imperative to link women entrepreneurs to business development services and increase their access to relevant technical education. The primary focus of Nepalese women entrepreneurs has to be shifted from the traditional sector of small and micro enterprises to larger sectors of technology and innovation. The use of the latest digital technology, to disrupt old ways of doing business, is the need of the hour. Therefore, 
the usage of computers and the internet and light semi-automated machineries must be promoted to increase the utility and production among the women entrepreneurs.

\section{CONCLUSIONS}

The entrepreneurial environment for women in Nepal is full of challenges. It is improving but at a snail's pace. The political uncertainty, corruption, strikes, bureaucracy, and unionization have greatly affected the entrepreneurial environment. The process of starting a new business is long and tedious. Not only do the political factors affect this, but also factors like societal, legal, economic imbalances have greatly affected the current situation for women who wish to enter into entrepreneurial positions. In addition, the society of Nepal views women as homemakers rather than as innovators or change makers. Some people even find the word, "women entrepreneurship" to be feminist and refuse to use it. Whereas some, who are genuinely trying to help, complain that women do not even try to seek out possible help due to inadequate market information or networks.

The civil society organization is working together with I/NGOs, like the United Nations, to decrease the gender gap by setting quotas for women to participate in professional development functions. The I/NGOs also help in training, providing networking opportunities, and giving options for financial aid to women entrepreneurs. The legal environment is trying to help women entrepreneurs to uplift their status through power distribution, living styles, and working environments. But, it is unclear who is actually utilizing those services and how many are benefiting from it.
Additionally, legal policies try to encourage women entrepreneurs, but according to the new Industrial Act of 2011, we can see the industry is employing more than 50 percent of women, socially excluded and those who are disabled to receive a 15 percent tax discount. Instead of promoting women entrepreneurs, the legal policies seem to rip them off by further adding documentation that is unnecessary and hard to come by and by not supporting them in ways that make a difference. Furthermore, the political environment of a country plays a vital role in the growth and expansion of businesses in any economy. Having an unstable political system will not just dampen entrepreneurial activity but will also affect the macroeconomic environment as a result. In Nepal, it has constrained both domestic and foreign investment, which has also stopped newcomers from entering into the entrepreneurial ecosystem.

Nepali women have to be seen as more than homemakers and need to be given equal rights (in practice) as suggested by the constitution of Nepal to establish and flourish their businesses. Only when the policies are made people-friendly, can more women be encouraged to join the entrepreneurial ecosystem. Current social norms must be changed. Regarding the policy amendments, the entrepreneurial and economic policies of countries like New Zealand, Hong Kong need to be studied and compared and contrasted with the Nepali policies, wherein the legal hurdles can be overcome. As Nepal's federal government stabilizes as grows, the political stability will further boost the entrepreneurial ecosystem in the country, providing women with more opportunities to enter into it. 


\section{REFERENCES}

Acharya, M. (2001). Women and the economy: The key issues. Retrieved from http://www.nepaldemocracy.org/gender/women_economy.htm

Bulsara, H. P., Chandwani, J., \& Gandhi, S. B. (2014). Women entrepreneurship and innovations in India: An exploratory study. International Journal Of Innovation - IJI, 2(1). doi:10.5585/iji.v2i1.2

Cohoon, J. M., Wadhwa, V., \& Mitchell, L. (2011). The anatomy of an entrepreneur: Are successful women entrepreneurs different from men? SSRN. doi:10.2139/ssrn.1604653

Corruption Perceptions Index 2016 (2017). In Transparency International. Retrieved from https://www.transparency.org/news/feature/corruption_perceptions_index_2016\#table

Creswell, J. (2013). Qualitative inquiry \& research design: Choosing among the five approaches. Thousand Oaks, CA: SAGE Publications.

Development of women entrepreneurship in Nepal. (2018, February 12). In Green Tick Nepal. Retrieved from http://gtn.com.np/development-of-women-entrepreneurship-in-nepal/

Dwibedi, L. (2015). Women entrepreneurship and innovations: A critical analysis. Academic Voices: A Multidiscipinary Journal, 5, 16-21. Retrieved from https://www.nepjol.info/index.php/AV/article/view/15846

Industrial Policy 2011. (2011). In Government of Nepal [GoN]. Retrieved from http://moi.gov.np/uploads/files/Industrial\%20Policy\%2C\%202010.pdf

Kumar, M., Navalgund, L. K., Mohan, C. H., \& Vijaya, C. (2013). The role of women entrepreneurship in modern world. International Journal of Current Engineering and Technology (1), 100-104. Retrieved from http://inpressco.com/wp-content/uploads/2013/09/Paper20100-104.pdf

Labour migration for employment a status report for Nepal: 2015/2016 - 2016/2017. (2018). In Department of Foreign Employment [DoFE].

Llorente, G. M., Lopez, M. B., \& Montes, C. (2011). Exploring the motivations of protesters in contingent valuation: Insights for conservation policies. Environmental Science \& Policy(14), 76-88.

Maskey, I. S. (2014). Socioeconomic status of women entrepreneurs in Kathmandu metropolis (Published dissertation). Kathmandu: Tribhuwan University (TU).

National population and housing census 2011. (2011). In Central Bureau of Statistics [CBS]. Retrieved from http://cbs.gov.np/image/data/Population/National\%20Report/National\%20Report.pdf

Nepal population clock (live). (2018, November 11). In United Nations. Retrieved from https://countrymeters.info/en/Nepal

Nepal slips 5 places in doing business. (2018, November 1). In The Himalayan Times. Retrieved from https://thehimalayantimes.com/business/nepal-slips-5-places-in-doing-business-index/

Sashikumar, B. (2017). An economic study of women entrepreneurship. International Journal of Current Research and Modern Education, 2(1). Retrieved from http://ijcrme.rdmodernresearch.com/wpcontent/uploads/2017/07/185.pdf

Sattar, S. (2010). Opportunities for men and women: Emerging Europe and Central Asia . Washington DC: The World Bank.

Shakya, M. (2008). Cultural capital and entrepreneurship in Nepal: The readymade garment industry as a case study. East Eisenhower Parkway: ProQuest.

Simoes, A. (2016). Nepal (NPL) Exports, imports, and trade partners. Retrieved from https://atlas.media.mit.edu/en/profile/country/npl/

Sorensen, J. B. (2006). Bureaucracy and entrepreneurship. Stanford, CA: Stanford University.

Thapa, B. R., Murayama, Y., \& Ale, S. (2008). City profile Kathmandu. CITIES - The International Journal of Urban Policy and Planning, 45-57.

Time required to start a business (days). (2016). In The World Bank. Retrieved from http://data.worldbank.org/indicator/IC.REG.DURS

Westcliff International Journal of Applied Research. Vol. 2, No. 2. Fall 2018 
The World Bank in Nepal-Overview. (2016). Retrieved from http://www.worldbank.org/en/country/nepal/overview

Tripathi, A. (2016, 14$)$. Nepal- China trade: Prospect and challenges. New Business Age. Retrieved from http://www.newbusinessage.com/MagazineArticles/view/1391

World Bank. (2018). Nepal systematic country diagnostic. Washington DC: The World Bank Group (The World Bank /International Financial Corporation /Multilateral Investmet Gurantee Agency).

World Bank [WB]. (2018). Doing Business 2019 : Training for reform-Nepal. Kathmandu: World Bank Group. Retrieved from http://www.doingbusiness.org/content/dam/doingBusiness/country/n/nepal/NPL.pdf

World Bank. (2017). Nepal-Country At a Glance. Retrieved from www.worldbank.org: http://www.worldbank.org/en/country/nepal 